\title{
LETRAMENTO: UM CONCEITO EM (DES)CONSTRUÇÃO E SUAS IMPLICAÇÕES/REPERCUSSÕES NA AÇÃO DOCENTE EM LÍNGUA MATERNA
}

\author{
LITERACY: A CONCEPT (IN)DECONSTRUCTION AND ITS IMPLICATIONS FOR \\ THE TEACHING PRACTICE OF THE MOTHER TONGUE
}

Mary Elizabeth Cerutti-Rizzatti

Universidade Federal de Santa Catarina

\begin{abstract}
Resumo
Este artigo focaliza o fenômeno do letramento. Trata-se de uma abordagem qualitativa, de vivência etnográfica, levada a termo com o objetivo de responder à seguinte questão de pesquisa: Que implicações/repercussões a (des)construção do conceito de letramento traz consigo em se tratando da atuação do profissional de língua materna na escola? O estudo empírico previu a vivência, ao longo de um semestre letivo, em duas escolas públicas de educação básica e a interação com seis profissionais, dentre os quais professores de língua materna e professores alfabetizadores. A ancoragem teórica constitui-se fundamentalmente de estudos de Street (1984; 1988; 2003), Barton (1994); Barton, Hamilton e Ivanic (2000) e Hamilton (2000). Os resultados apontam para impermeabilidades e permeabilidades ${ }^{1}$ no que respeita à ação docente concebida à luz de contribuições teóricas desse universo. As impermeabilidades parecem corresponder às propostas de hibridização entre letramentos locais e letramentos globais; já as permeabilidades revelam-se mais efetivamente na busca de compreensões menos instáveis em se tratando das relações entre letramento e alfabetização.
\end{abstract}

Palavras-chave: Letramento. Alfabetização. Ação docente em língua materna.

\begin{abstract}
This article focuses on the phenomenon of literacy. This qualitative and ethnographic approach aims at answering the following question: What are the implications of the (de)construction of the literacy concept for the practice of mother tongue teachers at schools? The empirical study was carried out over one semester at two primary education public schools and included interactions with six professionals, including Portuguese teachers and Literacy teachers. The theoretical background is based on Street (1984, 1988, 2003), Barton (1994), Barton, Hamilton and Ivanic (2000) and Hamilton (2000). The results indicate impermeability and permeability regarding teacher practice enlightened by theories from this field. The impermeabilities seem to correspond to hybridity proposals between local literacies and global literacies. The permeabilities, on the other hand, have been revealed by the teachers effort to more

\footnotetext{
1 Tomamos, para as finalidades deste estudo, os termos em questão com as seguintes acepções: permeabilidade: abertura do professor para dialogar com propriedade com as novas propostas conceituais; impermeabilidades: concepções docentes prototípicas, solidificadas historicamente e nãopermeáveis à dialogia com novas propostas conceituais.
} 
clearly understand the ways in which the concept of literacy can contribute to a more productive and informed literacy action.

Keywords: Literacy. Teaching/learning of reading and writing. Teaching practice in the mother tongue.

\section{INTRODUÇÃO}

O fenômeno do letramento constitui, em nossa compreensão, uma discussão que ganhou substancialmente espaço no Brasil sobremodo ao longo da década de 1990, para o que contribuíram publicações, de ampla repercussão nacional, de autoras como Ângela Kleiman e Magda Soares ${ }^{2}$, entre outros estudiosos do tema no país. Por meio de obras dessa natureza, tornou-se conhecido o movimento chamado Novos Estudos de Letramento - NLS, agasalhando trabalhos de Shirley Heath, Brian Street, David Barton e Mary Hamilton, para citar alguns dos nomes possivelmente mais referenciados no Brasil.

Em nível nacional, diferentemente do que se deu em outras nações, ganhou terreno um embate justificável em se tratando de dois conceitos que têm lugar na língua materna, letramento e alfabetização. No âmbito em que se instaurou esse embate, instaurou-se, também, um leque de outras questões, as quais, desde então, vêm suscitando toda sorte de posicionamentos, argumentação, críticas, ressignificações. Dentre elas, reputo como uma das mais instigantes, as fronteiras do conceito propriamente dito, ou seja, o que de fato é letramento? Ou, tornando a pergunta possivelmente mais "atual”: o que são letramentos?

É nosso objetivo, nesta reflexão, tentar responder não a essa questão propriamente dita dada, em nossa compreensão, a sua complexidade por ora -, mas responder a outra questão a ela correlata: Que implicações/repercussões a (des)construção do conceito de letramento traz consigo em se tratando da atuação do profissional de língua materna na escola? Para tanto, dividimos este artigo em duas seções: na primeira delas registramos uma reflexão teórica e, na segunda, apresentamos parte de um estudo cujo foco são essas mesmas implicações/repercussões.

\section{IMPLICAÇÕES INERENTES À (DES)CONSTRUÇÃO DO CONCEITO DE LETRAMENTO}

Entendemos que a língua escrita é uma modalidade de status recente no território da Linguística, e, para muitos profissionais da área, possivelmente ela continue a ser objeto marginal. A despeito de posicionamentos dessa ordem e sob os auspícios do que entendemos ser a Linguística Aplicada hoje ${ }^{3}$, lançamo-nos na interface com a antropologia e com a etnografia, na busca de entender o que seres humanos reais, situados no tempo e no espaço, fazem com a língua escrita em uma época em que essa

\footnotetext{
${ }^{2}$ A exemplo de Letramento: um tema em três gêneros, uma publicação da Editora Lê, de Belo Horizonte, de autoria de Magda Soares, tanto quanto a exemplo de Os significados do letramento, publicação da Mercado das Letras, de Campinas/SP, organizada por Ângela Kleiman.

${ }^{3}$ Como propõem, entre outros autores, autores como Rajagopalan (2006), Signorini (2006) e Moita Lopes (2006).
} 
modalidade tem, sobretudo no universo da tecnologia, se enovelado progressivamente com a fala ${ }^{4}$.

Os convites de Street (1984; 1988; 2003) para que nos aproximemos de seres humanos datados e fisicamente situados que interagem por meio da escrita aqui e em (quase) todo o planeta motivaram e continuam a alimentar estudos sobre letramento, fenômeno concebido - tal qual hoje admitem inclusive dicionaristas do Instituto Houaiss $(2001)^{5}-$ como o uso da escrita na sociedade. Tomar a escrita na perspectiva do uso implica inerentemente uma concepção de língua como objeto social e requer disposição para lidar com sujeitos reais, datados e situados geograficamente. Barton, Hamilton e Ivanic (2000) entendem que os letramentos são situados, o que causa desconforto em alguns estudiosos $^{6}$, em razão possivelmente do temor do determinismo e do relativismo que parecem nos assombrar quando assumimos olhar os universos locais em suas particularidades. Sobre isso, escreve Street (2003, p. 10-11):

Se, por um lado, muitos educadores e idealizadores de políticas vêem o letramento como sendo uma habilidade meramente neutra, igual em qualquer lugar e a ser distribuída (quase que injetada em alguns discursos baseados em idéias médicas) ${ }^{7}$ para todos em iguais medidas, o modelo ideológico reconhece que as decisões políticas e em educação precisam estar baseadas em julgamentos prévios sobre que letramento deve ser distribuído, e por quê. Assim sendo, a pesquisa de caráter etnográfico não sugere que as pessoas sejam simplesmente deixadas como estejam, com base no argumento relativista de que um tipo de letramento é tão bom quanto o outro. Mas também não sugere que as pessoas simplesmente devem "receber" o tipo de letramento formal e acadêmico conhecido pelos responsáveis pela determinação de políticas e que, de fato, muitas delas já terão rejeitado. "Fornecer" esse tipo de letramento formalizado não levará à atribuição de poder, não facilitará novos empregos e não gerará mobilidade social.

A interpelação sobre o global, na maioria das vezes, impõe-se intempestivamente. Brandt e Clinton (2002) criticam os Novos Estudos do Letramento sob o argumento de que tais estudos ficaram tão preocupados em destacar o caráter local das práticas de letramento, com vistas à fuga do modelo autônomo, que perderam uma dimensão mais ampla de teorização. Segundo as autoras, há exagero no poder conferido aos contextos locais, isso porque as práticas de letramento não são tipicamente inventadas por quem as vivencia, tanto quanto não são independentes dos artefatos que as sustentam

Em resposta, Street (2003, p. 11) argumenta: “A combinação de local/global que um programa de transformação baseado na abordagem etnográfica poderia desenvolver é bastante diferente da visão romântica do paraíso 'folclórico' a ser deixado puro e impoluto através da interferência urbana ou moderna, como argumentaria a crítica ao 'romanticismo'.” Segundo ele,

\footnotetext{
${ }^{4}$ Tomem-se recursos síncronos de interação on-line como exemplo.

5 “[...] conjunto de práticas que denotam o uso de diferentes tipos de material escrito.” (HOUAISS, 2001, p. 1747)

${ }^{6}$ A exemplo de Brandt e Clinton (2002).

${ }^{7}$ Barton (1994) discute amplamente essas metáforas e aponta a idéia de “erradicação” como ilustrativa da metáfora médica: erradicação de analfabetismo, por exemplo, teria subjacente a concepção de que o não-domínio dos sistemas escritos teria componentes relativos a endemias.
} 
o que pertence ao global não chega aos contextos locais com sua força e significado intactos, havendo uma necessária hibridização dos letramentos. E prossegue: "É isso, então, o que se quer dizer por ver o lado de fora ou o global como estando incluído no 'local': é nesses níveis, em vez de - como talvez em alguns conceitos dominantes - considerar o local como algo insular, estreito, embutido, resistente.” Parece-nos evidente a perspectiva dialética presente no conceito de hibridização. Novamente Street (2003, p. 10):

Esse tipo de pesquisa [de natureza etnográfica], ao indicar o valor dos letramentos locais e ao auxiliar leitores e observadores a enxergar o que talvez tivessem deixado de ver antes, nos usos cotidianos do letramento por grupos marginalizados em ambientes tanto rurais quanto urbanos, podem parecer exacerbar esses usos locais em detrimento dos letramentos padronizados mais poderosos. Os desenvolvedores olham para esses letramentos locais como sendo simples práticas "folclóricas", que precisarão ser substituídas para que o desenvolvimento possa avançar, e para que possa ser realizada a promessa de "progresso" - em saúde, empregos, direitos políticos etc. Os etnógrafos do letramento, entretanto, argumentariam que o respeito demonstrado em sua abordagem não deve ser confundido com romanticismo, ou com abordagens "folclóricas". A abordagem etnográfica não envolve um compromisso simplesmente com o status quo: ao contrário, os pesquisadores mostram-se comprometidos com transformação social - que foi na verdade a raiz de seu engajamento.

Esse embate entre o local e o global talvez possa ser associado ao que chamamos, nesta reflexão, de externalidade. Os Novos Estudos de Letramento propõem o trabalho etnográfico como opção metodológica produtiva para a compreensão e ressignificação do que as pessoas fazem com a escrita, tanto quanto para compreensão/ressignificação dos sentidos dessa modalidade da língua em suas vidas. Essa opção implica interface com outros ramos do conhecimento humano; assim, estudar a escrita requer permeabilidade a construtos teóricos da antropologia e da sociologia, para mencionar apenas alguns exemplos. Entender o que os homens fazem com a escrita implica entender os homens na configuração social, cultural e histórica em que vivem.

Compreendemos que esse olhar, digamos, aberto a externalidades da língua escrita, explica, sob vários aspectos, a concepção de letramentos no plural (STREET, 2003; BARTON, HAMILTON, IVANIC, 2000; ROJO, 2009; OLIVEIRA e KLEIMAN, 2008). Barton (1994, p. 29) propõe a metáfora da ecologia para tratar do tema, concebendo que o uso da língua escrita é parte do contexto em que se processa, influenciando e sendo influenciado por esse contexto. Escreve o autor: "An ecological approach takes as its starting-point this interaction between individuals and their environments." E ainda: "An ecological approach emphasizes diversity, and in the original biological senses of ecology, sees it as a virtue. Diversity is a source of strength, the roots of the possibilities of the future."” (p. 31) Já Barton, Hamilton e

\footnotetext{
8 Uma abordagem ecológica toma como ponto de partida essa interação entre os indivíduos e seus ambientes.

${ }^{9}$ Uma abordagem ecológica enfatiza a diversidade e, no sentido biológico original da ecologia, a vê como uma virtude. A diversidade é uma fonte de força, a raiz de possibilidades futuras.
} 
Ivanic (2000, p. 1) escrevem: "Literacies are situated. All uses of written language can be seen as located in particular times and places. ${ }^{10,}$

Essa compreensão pluralizada acerca dos usos sociais da escrita chama a atenção para a diversidade, as idiossincrasias que tais usos revelam nos diferentes espaços e tempos em que se dão, envolvendo sujeitos situados espacial e historicamente, o que, em nossa compreensão, é legítimo e difícil de refutar por parte de quem opta por estudar a língua no plano interacional e enunciativo. Tomar a escrita na externalidade - no movimento dialético entre o local e o global -, entendida aqui como o lócus em que se concretiza e em benefício de quem se faz instrumento, parece, porém, ter seus custos. O maior deles, em se tratando da (des)construção do conceito, em nossa compreensão, é a amplificação desmesurada das fronteiras que abarca, suscitando conceitos derivados como letramentos eletrônicos, letramentos ecológicos ${ }^{11}$, letramentos matemáticos e itens afins.

Ainda que tenham sua lógica, o que tributamos à perspectiva de acesso a conhecimento, inclusão, cidadania - processos, em nossa compreensão, implicados nas discussões sobre letramento dada sua ancoragem social - tais derivações parecem não conter um ingrediente fundamental, o qual justificou, em grande medida, o advento e a projeção do conceito de letramento no Brasil e internacionalmente: interação com base no signo verbal escrito. É legítimo que se discutam outros sistemas semióticos, mas não entendemos possível uma externalidade de natureza tão ampla: em nossa compreensão, para tratarmos de letramento, o signo verbal escrito tem de estar presente de modo prevalecente - mesmo que como objeto de escuta, a exemplo das discussões de Heath (1982) sobre leitura de livros de história para crianças -, o que não ocorre em boa parte dessas derivações.

A contraface dessa ampliação do universo referencial que o conceito abarca quando tomado no plano da externalidade parece ser a absoluta imanência ${ }^{12}$. Entendemos que há interpenetrações entre esses focos, tanto quanto há especificidades, tal qual propõe Street, em citação que veiculamos anteriormente. Entendemos, ainda, que o foco da externalidade e o foco da imanência suscitam remissões, respectivamente, aos modelos ideológico e autônomo de letramento, os quais, com base em Street (2003), não vemos como dicotômicos. Escreve o autor (2003, p. 9):

[...] os modelos jamais foram propostos como opostos polares: em vez disso, o modelo ideológico de letramento envolve o modelo autônomo. A apresentação do letramento como sendo "autônomo" é apenas uma das estratégias ideológicas empregadas em associação ao trabalho no campo do letramento, que em realidade disfarça a maneira em que a abordagem supostamente neutra efetivamente privilegia as práticas de letramento de grupos específicos de pessoas. Nesse

\footnotetext{
10 Letramentos são situados. Todos os usos da linguagem escrita podem ser vistos como localizados em determinadas épocas e lugares.

${ }^{11}$ Kleiman (2006, p. 186) propõe o conceito de letramento ambiental, mas o faz tendo o signo verbal escrito em foco: “[...] isto é, a leitura de textos curtos, informativos, propagandísticos sobre assuntos do cotidiano, como outdoors, placas, manchetes de jornais locais, avisos [...]"

${ }^{12}$ Imanência, aqui, é entendida como asséptica ao contexto, comprometida com a dimensão sistêmica da língua.
} 
sentido, o modelo autônomo mostra-se profundamente ideológico. Ao mesmo tempo, o modelo ideológico consegue perceber as habilidades técnicas envolvidas, por exemplo, na decodificação, no reconhecimento das relações entre fonemas e grafemas e no engajamento nas estratégicas aos níveis de palavras, sentenças e de textos [...]. Entretanto, o modelo ideológico reconhece que essas habilidades técnicas estão sempre sendo empregadas em um contexto social e ideológico, que dá significado às próprias palavras, sentenças e textos com os quais o aprendiz se vê envolvido.

Sob o olhar de imanência que registramos aqui, um cidadão só pode participar de eventos de letramento se estiver alfabetizado. Sob essa lógica, a nosso ver perfeitamente legítima no plano do letramento escolar, mas insustentável no plano do letramento tomado como fenômeno mais amplo e também insustentável na concepção de modelo ideológico (STREET, 1984; 1988; 2003), o domínio do sistema é condição sine qua non para atribuir a alguém a condição de letrado.

Evidentemente, nas sociedades grafocêntricas contemporâneas, não poderia fazer parte do ideário científico qualquer defesa em favor da manutenção do analfabetismo - quer pleno ou funcional -, fazendo-o em nome do respeito ao uso singular que os sujeitos evidenciam em se tratando da escrita. Remissões anteriores ao pensamento de Brian Street devem ter deixado isso claro. Um despropósito dessa ordem, no entanto, não pode ser tomado como necessariamente subjacente à concepção de que sujeitos que se movem nas sociedades atuais usando de algum modo a escrita mesmo sem dominar 0 sistema alfabético são sujeitos letrados desde que tomem parte de eventos de letramento. Para que a lógica desse olhar seja compreendida sem deturpações desse tipo, importa que se assumam conceitos como práticas e eventos de letramento, tal qual propõem Heath (1982), Street (1988; 2003) e Barton (1994), marcando tratar-se de uma acepção incompatível com o conceito de letramento escolar, mas convergente com o conceito mais amplo de letramento, tomado como fenômeno social - no bojo do qual, em nossa compreensão, alojam-se letramentos de toda ordem, inclusive o letramento escolar, na interpenetração a que fizemos menção anteriormente.

A relevância dessa lógica, em nosso entendimento, está na possibilidade de compreensão de como expressivos contingentes populacionais alijados dos processos de escolarização plena conseguem (ou não) interagir via modalidade escrita em sociedades crescentemente grafocêntricas; questão, a nosso ver, importante se considerada a condição de inúmeras nações pobres que, em maior ou menor proporção, vivem a centralização da escrita contemporaneamente. Uma descrição analítica dos usos que analfabetos fazem da escrita em seu cotidiano nessas mesmas sociedades seguramente é foco de interesse de quem se ocupa de entender o que as pessoas fazem com a escrita em sua vida cotidiana e a que se presta essa modalidade em se tratando da ação humana. Afinal, tal qual propõe Hamilton (2000a), os eventos de letramento - usos, digamos, visíveis da escrita - são a ponta do iceberg cuja base são as práticas de letramento, as quais traduzem valores, ideologias, modos de vida. Soares (1998), tanto quanto Kleiman (1995) - ambos textos seminais no Brasil - já assinalavam a possibilidade de participação, de sujeitos nessa condição, em atividades nas quais a língua escrita está sendo usada. Tfouni (1995) vai mais longe ao questionar o conceito de iletrado nas sociedades atuais. 
Essa, porém, parece-nos apenas uma das muitas questões implicitadas em se tratando do foco que aqui chamamos de imanência. Outra dentre essas questões, possivelmente mais recorrente nas discussões na esfera educacional, são similitudes e dissimilitudes no que respeita a alfabetização e letramento. Trata-se de um tema com especial interesse em nosso país, dadas as delicadas condições de alfabetismo, tal qual mostra o Relatório do INAF $^{13}$, bem como dado o recorte que os signos alfabetização e letramento, em nossa compreensão, fazem no universo referencial a que correspondem.

Compartilhamos plenamente a visão de que, sem o domínio do código, não há alfabetização. Esse domínio, colocado em xeque por alguns pares de anos, em razão, supomos, de compreensões equivocadas de ação didática desenvolvidas a partir de paradigmas construtivistas ${ }^{14}$, ganha novamente o lugar de importância que nunca deveria ter perdido no cenário nacional; hoje, ao que parece, à luz de descobertas neurocientíficas. ${ }^{15}$

Concebemos, no entanto, que esse entendimento não autoriza uma concepção de alfabetização que descure dos significados da escrita tal qual eles se dão na realidade cotidiana. As várias décadas de reflexões acerca da necessidade de a escrita significar para a criança ao longo do processo de alfabetização, a nosso ver, em que pesem equívocos metodológicos, não podem ser denegadas, sob pena de, mais uma vez, assistirmos à perda do tão necessário equilíbrio entre uso social da escrita e domínio do código. Aqui, entendemos, o conceito de letramento ganha especial significado ${ }^{16}$.

Muitos têm sido os posicionamentos acerca das distinções/aproximações entre esses dois processos/fenômenos - alfabetização e letramento $^{17}$. Não estamos seguros, no entanto, de que haja satisfatórios compartilhamentos entre estudiosos da área acerca de tais distinções/aproximações. A nosso turno, questionamos expressões como alfabetização para o letramento, alfabetização com letramento ${ }^{18}$ e itens afins, que dicotomizam ambos os fenômenos e lhes conferem um perigoso fracionamento (alfabetização com letramento), sugerindo a possibilidade de haver alfabetização sem uso social da escrita, ou uma tautológica finalidade (alfabetização para o letramento) e para que outra função se prestaria? Trata-se de uma visão dicotômica quando, em nossa compreensão, deveria ser dialética. Se letramento for tomado como fenômeno mais amplo, deve "agasalhar" em si o processo de alfabetização, em uma possível relação continente $X$ conteúdo, ou seja, o processo de alfabetização seria um componente do amplo fenômeno do letramento - aqui, no singular -, mais especificamente, um componente do letramento escolar, o qual por sua vez, seria um dos muitos letramentos de que o fenômeno maior, letramento, se constitui. Estamos, porém, ao que parece, muito longe de compartilhamentos mais estáveis acerca dessas diferenças, e o que registramos aqui não é mais que o nosso olhar.

\footnotetext{
${ }^{13}$ Indicador Nacional de Alfabetismo Funcional (2009): (www.ipm.org.br)

${ }^{14}$ Referimo-nos, aqui, a abordagens tangenciais do pensamento de Ferreiro e Teberosky (1985).

${ }^{15}$ Veja-se, sobre isso, teorizações de Dehaene (2007), cujo pensamento tem sido divulgado no Brasil pela psicolinguista Leonor Scliar-Cabral (UFSC).

${ }^{16}$ O programa Pro-letramento, do Governo Federal, parece buscar essa conciliação, dada a relevância que atribui ao domínio do código, sugerindo que isso deva se dar em contextos de sentido para a criança.

${ }^{17}$ Vejam-se sobre isso Tfouni (1995); Soares (2004a;2004b), Rojo (1998).

18 O programa Pró-letramento, a despeito de seus predicados, incorre nessa que entendemos ser uma impropriedade.
} 
A vinculação de letramento à escolarização e à erudição é o que possivelmente explique também a idéia de gradação e de nivelamento nos estudos sobre o conceito. Compreendemos que o conceito de letramento tal qual proposto pelos NLS não é compatível com a idéia de gradação, a qual implica hierarquização. Entendemos que a figura da gradação e a figura do nivelamento são admissíveis - senão esperadas - em se tratando do letramento escolar, universo em que a erudição pode ser, sob vários aspectos, mensurada, o que autoriza alegorias dessa natureza. No plano mais amplo do letramento, concebido como fenômeno multifacetado, entendemos que não é possível admitir hierarquizações, o que suscitaria valoração cultural. Escreve Barton (1994, p. 38): "[...] different practices cluster into coherent groups it is very useful to talk in terms of them as being different literacies. A literacy is a stable, coherent, identifiable configuration of practices such as legal literacy, or the literacy of specific workplaces."19

Ao que parece, a instauração do conceito de letramento trouxe consigo tantos ganhos quanto desafios, o que possivelmente justifique a opção de muitos autores em tratar de cultura escrita e não de letramento ${ }^{20}$; atitudes dessa natureza, em nossa compreensão, têm implicações bem mais substantivas do que mera seleção lexical, estendendo-se ao universo escolar, o qual, em nosso entendimento, poderia ter ganhos expressivos a partir dessas discussões. Em lugar disso, no entanto, observamos impermeabilidades preocupantes e, por outro lado, permeabilidades desconcertantes, como discutiremos a seguir.

\section{IMPLICAÇÕES/REPERCUSSÕES DAS DISCUSSÕES DE LETRAMENTO NA AÇÃO DOCENTE EM LÍNGUA MATERNA}

Tendo procedido a essa reflexão teórica - permitindo-nos muito mais diálogos do que resenhas -, passamos à discussão da abordagem empírica deste estudo. Trata-se de uma pesquisa qualitativa, pautada em vivência etnográfica (MASON, 1996) em duas escolas públicas de educação básica no norte da ilha, no município de Florianópolis. Permanecemos nessas instituições ao longo de um semestre letivo - em vivências assistemáticas que atenderam a horários e eventos previstos no calendário escolar -, convivendo com um grupo de alfabetizadores e professores de Língua Portuguesa - seis no total - em reuniões pedagógicas, cursos de formação, momentos de interação e no desenvolvimento de aulas. Os instrumentos de geração de dados foram a observação participante e as notas de campo. (OLABUENÁGA; IZPIZUA, 1989) Um dos nossos objetivos na ocasião corresponde ao foco deste artigo - responder à seguinte questão de pesquisa: Que implicações/repercussões a (des)construção do conceito de letramento traz consigo em se tratando da atuação do profissional de língua materna na escola? A organização dos dados gerados em campo para responder a essa questão requereu o desdobramento de nosso olhar em três focos distintos: a) planejamentos institucionais delineados a priori $\mathrm{X}$ planejamentos institucionais sensíveis aos letramentos locais; $\mathrm{b}$ ) atividades pedagógicas potencialmente ressignificadoras das práticas de letramento $\mathrm{X}$ atividades pedagógicas ancoradas em concepção universalista de língua escrita; e c)

\footnotetext{
${ }^{19}[. .$.$] diferentes práticas reunidas em grupos coerentes favorecem a discussão em termos de diferentes$ formas de letramento. Um letramento é uma estável, coerente e identificável configuração de práticas tais como letramento legal ou o letramento específico de lugares de trabalho. Em situações multilíngues, diferentes letramentos estarão frequentemente associados com diferentes línguas ou diferentes roteiros.

${ }^{20}$ Emília Ferreiro (2003) é exemplo dessa opção.
} 
alfabetização tomada na imanência X alfabetização como conteúdo e letramento como continente.

Com relação a planejamentos institucionais delineados a priori $X$ planejamentos institucionais sensíveis aos letramentos locais, importa considerar que, em nossa compreensão, uma das questões mais relevantes para o universo escolar, em se tratando dos estudos do letramento, é a defesa de um olhar sensível às práticas de letramento, entendidas, segundo Hamilton (2000a), como a maneira por meio da qual as culturas realizam os eventos de letramento; grupos culturais distintos lidam de forma diferenciada com os usos e as práticas sociais de escrita. Essas teorizações parecem sinalizar para a necessidade de os professores - tanto quanto a escola em sua configuração mais ampla - conhecerem as práticas de letramento locais, o que implica, em última instância, conhecer os letramentos locais, tal qual propõe Street (2003).

Nossa expectativa era encontrar esse olhar sensível nos Projetos Político-pedagógico das duas escolas, considerando que, em documentos desse tipo, há espaços específicos para a descrição da comunidade escolar, o que inclui a realidade sociocultural, econômica e o delineamento histórico dos agrupamentos humanos ali instalados. Tais espaços não são gratuitos, dada a suposição de que o planejamento escolar partiria do conhecimento dessa configuração. O material a que tivemos acesso em uma das escolas, porém, a exemplo do que inferirmos acontecer em outros tantos estabelecimentos de ensino, foi construído por um grupo de profissionais que se dispuseram a fazê-lo em tempo recorde - dadas as exigências institucionais - para atender a demandas de instâncias hierarquicamente superiores. A fala de uma dessas profissionais, registrada em nota de campo, ilustra com objetividade essa condição:

O PPP foi feito em um mês. Nós quatro nos reunimos e produzimos o documento usando as informações de outros planos existentes na escola.

Interpelada acerca da convivência com a comunidade, a professora ofereceu-nos estatísticas precisas, números exatos e descrições bastante satisfatórias da organização demográfica, da geografia, dos índices de violência e itens afins, revelando nunca ter tido contato com os moradores fora dos muros da escola. Os dados derivavam de documentos institucionais sobre aquela comunidade. Na outra escola, esse planejamento estava em reconstrução e tivemos oportunidade de influir no sentido de que a comunidade fosse objeto de maior atenção.

Nossa convivência com os professores nos fez entender a restrição a interações intramuros evidente em ambas as escolas: a violência nos locais era expressiva, e os professores, em sua maioria moravam em áreas bastante distantes dali. Ficou claro, em nossa vivência nas escolas, que conhecer as práticas de letramento daqueles núcleos urbanos requereria estar com eles em alguma medida. A não-convivência fazia com que os profissionais em questão, a exemplo possivelmente de um bom número de outros professores no país, inferissem os conhecimentos daqueles cidadãos sobre a língua escrita, delineando as práticas de letramento locais provavelmente com base em estereótipos sobre comunidades dessa natureza, os quais grassam no senso comum. 
Retomemos, aqui, as considerações de Street (2003, p. 10) a que fizemos remissão anteriormente. Segundo o autor, "[...] as decisões políticas e em educação precisam estar baseadas em julgamentos prévios sobre que letramento deve ser distribuído, e por quê.” Ainda que a ideia de distribuição de letramento não nos agrade porque suscita passividade (e estamos seguros de que não é esse o objetivo do autor), entendemos, tal qual Street, que não é possível universalizar práticas construídas a priori, na suposição de que "funcionem" em todos os contextos. De novo, retomando o autor: "'Fornecer' esse tipo de letramento formalizado não levará à atribuição de poder, não facilitará novos empregos e não gerará mobilidade social.” (p.10), possivelmente porque, na maioria das vezes, a ele são apresentadas resistências de toda ordem. Esse processo parece ganhar especial significado em se tratando de populações marginalizadas socioeconomicamente nas quais se revelam altos índices de violência, como acontece nas comunidades escolares em questão.

No que respeita a atividades pedagógicas potencialmente ressignificadoras das práticas de letramento $X$ atividades pedagógicas ancoradas em concepção universalista de língua escrita, outro enquadramento de nosso olhar para fins de discussão e que tem profundas relações com o item imediatamente anterior, pareceu-nos notória a impossibilidade de as escolas promoverem essa ressignificação em razão sobremodo de não conhecerem de fato as práticas de letramento daquelas comunidades específicas. A convivência nas instituições e a interação com os profissionais nos fez testemunhar uma concepção universalista de língua escrita, a qual perpassava aulas, planejamento, discussões pedagógicas e até mesmo cursos de formação.

Episódios bastante bem delineados, registrados em vinhetas narrativas em nossas notas de campo, permitem-nos concluir a assepsia das ações pedagógicas em se tratando da permeabilidade aos letramentos locais (BARTON, HAMILTON, IVANIC, 2000). Um dos projetos de alfabetização que acompanhamos, realizado ao longo do mês de setembro, tematizava a árvore, constituindo possivelmente um dos exemplos mais emblemáticos de ações pedagógicas universalistas. O planejamento docente da aula incluía a exposição de um tronco de árvore desenhado em papel cartão. Às crianças competia, após toda uma bela discussão sobre frutas, sucos, saúde - incluindo a presença de frutas na sala e a produção de suco de laranja -, montar o nome de uma fruta cujas letras desordenadas lhes haviam sido entregues pela alfabetizadora. Tendo montado o nome da fruta, os alfabetizandos deveriam colar a palavra na árvore, à guisa de copa. A atividade desenvolvia-se com sucesso, atendendo ao objetivo - que, em última instância era o domínio componencial do sistema alfabético em contextos de sentido -, quando uma menina colou a palavra laranja no cartaz. A professora perguntou: “Quem gosta de bolo de laranja?” Uma ou duas crianças levantaram a mão. Uma das meninas disse que nunca havia comido bolo de laranja, o que teve eco na voz de outras tantas. Alguém perguntou: “Como se faz bolo de laranja?” A professora, então, enveredou por uma discussão que culminou na alusão a receitas culinárias. Ao fim e ao cabo, tornou-se evidente que a maior parte das crianças nunca tinha tido contato, não apenas com bolo de laranja, mas com receitas culinárias; não sabiam que gênero era esse e nunca tinham visto o artefato (HAMILTON, 2000a) em que se consolida. As aulas do projeto, no entanto, prosseguiram com canções, poemas, histórias em quadrinhos, tal qual havia acontecido em anos anteriores. Não houve receitas culinárias e possivelmente se tenha perdido uma interessante oportunidade de vivência de um evento de letramento tão disseminado no plano global, mas 
desconhecido no plano local (STREET, 2003), em que pese a artificialidade da receita culinária na escola.

Outra de nossas vinhetas recupera uma cena em sentido contrário. Uma das crianças do sexto ano chegou esbaforida, distribuindo a todos um estranho panfleto que não se parecia com nada que havíamos visto até então. Fora incumbida por alguém de distribuir o material, mas parecia ter de fazer isso sem que fosse percebida por gestores e professores. Tivemos contato com o artefato (HAMILTON, 2000a) em razão da celeuma causada e de a professora ter tido de "confiscar" o material para reaver a ordem na classe.

De posse do panfleto e após um tempo relativo para construir os sentidos daquele conteúdo, entendemos tratar-se de um misto de ingresso, cartão de pontuação para bônus e certificado de sociedade do clube local. Tratava-se de um documento de distribuição quinzenal dentre os jovens da comunidade que lhes permitia acesso a um número específico de "matinês", exigindo, em contrapartida, a realização de serviços em favor do clube, o que lhes rendia a pontuação requerida para o ingresso nas baladas de maior preço, em que havia Djs famosos por ali. Aquele pequeno panfleto, de circulação consensual, amplamente conhecido na comunidade, continha tanta complexidade - dada a funcionalidade múltipla de que se revestia - que exigia raciocínio de engenharia para compreender. As quininhas, como eles os chamavam, pararam na mesa da direção, e os meninos encarregados de os distribuírem levaram para casa, não a quininha, mas uma advertência. Parece, na mão inversa, que o universo global perdeu uma interessante oportunidade de se deixar permear pelo universo local. $\mathrm{O}$ artefato em questão, dada sua especificidade e circunscrição àquela esfera de circulação, não teria legitimidade suficiente para ser objeto de atenção pedagógica? Considerando tratar-se de um recurso de escrita de ampla (e ovacionada) circulação local, não poderia constituir uma ponte para que aqueles garotos - na maioria leitores sofríveis e escritores titubeantes - se interessassem pela escrita? A propósito, a redação do panfleto mantinha instigante "respeito" à norma padrão escrita, e sua configuração era interessantemente funcional.

Finalmente, com relação a nosso terceiro enquadramento, alfabetização tomada na imanência $X$ alfabetização como conteúdo e letramento como continente, ficaram bastante evidentes nesse tempo de convivência com as escolas os impasses na compreensão dos alfabetizadores acerca de suas opções metodológicas. Interpelados sobre o que compreendiam ser a alfabetização hoje, alternavam-se em discursos prototípicos evocando cidadania, letramento, parâmetros curriculares, sem muita segurança acerca do que efetivamente enunciavam. Na prática, nossa observação participante nos mostrou três movimentos distintos, a seguir descritos com enfoque na produção textual, dada a limitação de espaço típica de um artigo. O primeiro movimento revela opção pela priorização do sistema alfabético ensinado em contextos fragmentários e descontextualizados, do que decorriam produções textuais como a que segue, fruto do comando clássico "recorte as figuras e escreva sobre elas" 


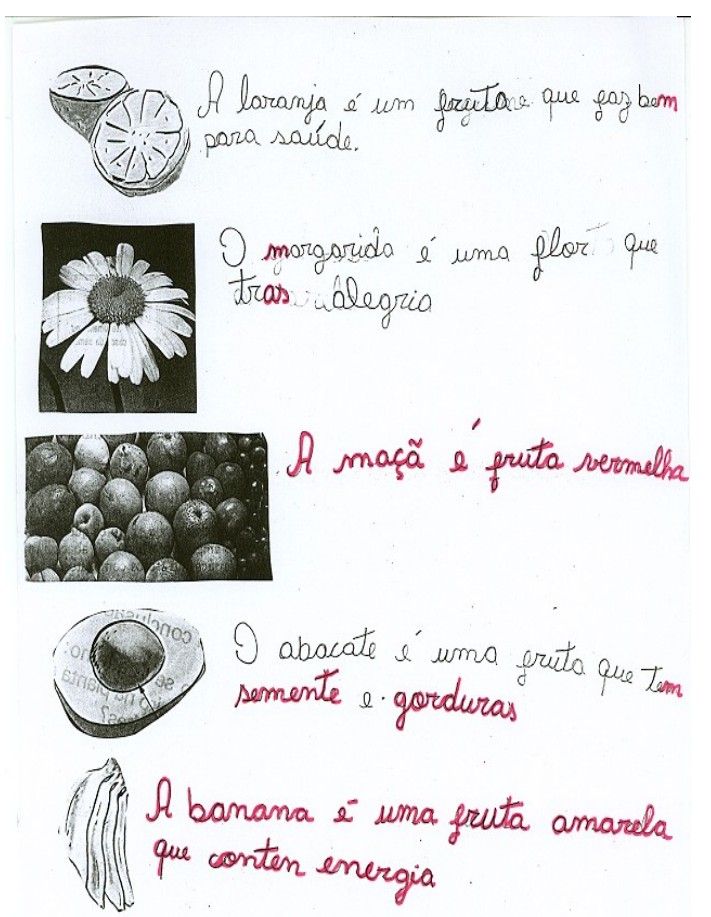

O segundo movimento revela opção por uma abordagem $m i s t a^{21}$, que oscila entre o foco no sistema alfabético e o foco na textualização, fazendo-o sem sistematicidade evidente, do que parece redundar, como mostra o texto a seguir, um domínio precário tanto de um quanto de outro componente. O comando era "folhear uma revista que haja em casa, escolher uma figura e escrever sobre”.

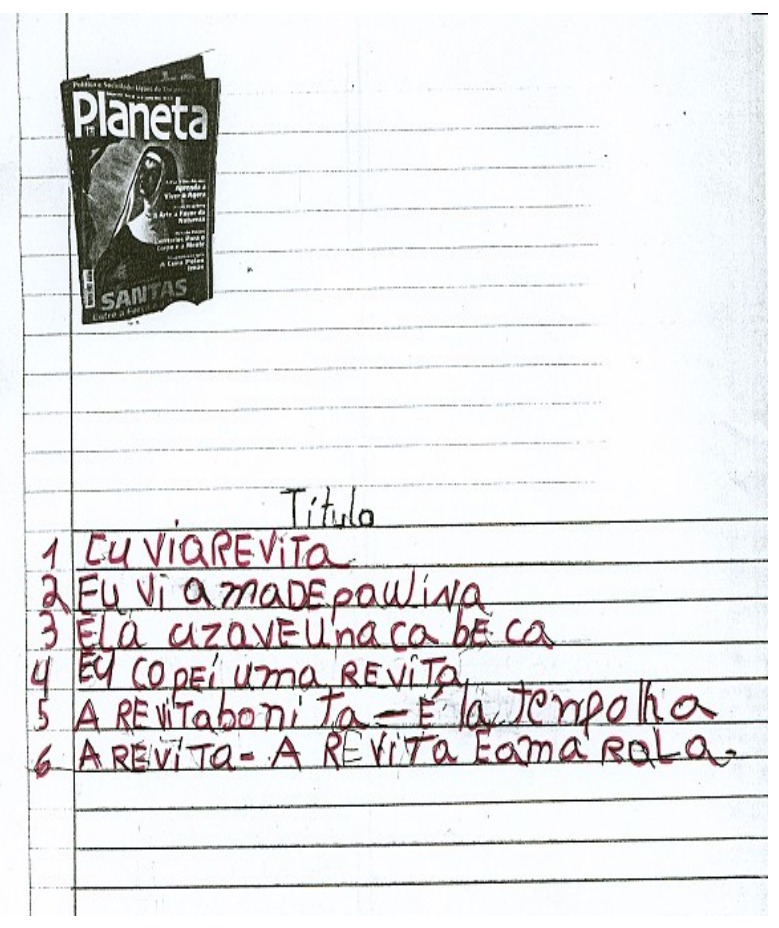

${ }^{21}$ À falta de designação mais apropriada. 
O terceiro movimento, explicitado no texto a seguir, é fruto de uma ação consequente, bem planejada e sistemática em que o sistema alfabético é ensinado em contextos de sentido, por meio de projetos temáticos, organizados cuidadosamente. Observamos que as crianças que participam desse movimento não dominam o código tal qual o fazem as crianças do primeiro movimento registrado aqui, mas, diferentemente daquelas, parecem saber que a língua escrita tem uma função: nesse caso, contar uma história. Nesse movimento entendemos explicitada a proposta de alfabetização como conteúdo e letramento como continente, dado estar bastante evidente a compreensão de que não há alfabetização sem domínio do código alfabético, mas que isso é parte de um fenômeno maior, que é a funcionalidade da língua escrita na vida humana.

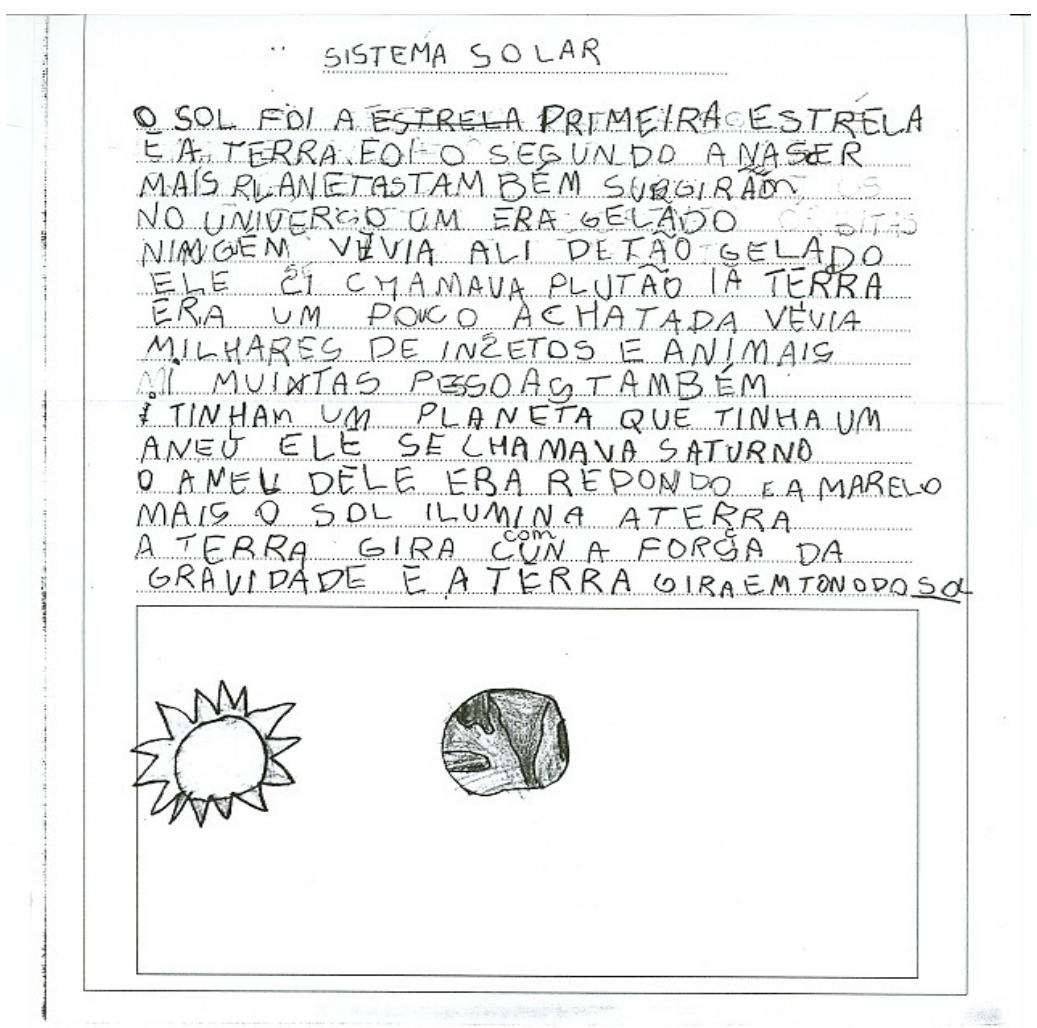

\section{CONSIDERAÇÕES FINAIS}

Parecem custosas as discussões sobre letramento na atualidade, sobretudo quando tentamos empreendê-las de modo crítico, o que exige que coloquemos "a navalha na carne", admitindo as tantas impropriedades e os tantos embates que o conceito tem gerado/suscitado - impropriedades e embates no bojo dos quais estão externalidades excessivas (letramentos matemáticos?) tanto quanto imanências refreadoras (só participa de um evento de letramento quem é alfabetizado?). Esses contornos seriam meramente discussões acadêmicas a alimentar vaidades de toda ordem, não fossem implicações/repercussões que parecem ter na escola real, universo que, quando impermeável às discussões, termina por abrir mão de oportunidades promissoras de hibridização dos letramentos globais e locais (tal qual se dá com a receita culinária e com as quininhas ) e, quando permeável a elas, termina por não saber exatamente como agir (assistematicidade no processo de alfabetização em nome de não-distinções entre 
letrar e alfabetizar - distinções ou interpenetrações? Eis mais um embate.) Valem, pois, novas incursões nesse universo, se não por outras razões, pelo tanto de vida humana que pulsa nele.

\section{REFERÊNCIAS}

BARTON, David. Literacy - an introduction to the ecology of written language. Cambridge/USA: Brackwell, 1994. .; HAMILTON, M.; IVANIC, R. Situated literacies. London: Routledge, 2000.

BRANDT, Deborah; CLINTON, Katie. Limits of the local: expanding perspectives on literacy as a social practice. Journal of Literacy Research, v. 34, n. 3, p. 337-356, 2002.

DEHAENE, S. Les neurones de la lecture. Paris: Odile Jacob, 2007.

FERREIRO, Emília. Entrevista à revista Nova Escola. Nova Escola. São Paulo, edição 162, maio de 2003.

Médicas, 1985.

TEBEROSKY, Ana. Psicogênese da língua escrita. Porto Alegre: Artes

GILLIEN, Julia; BARTON, David. Digital literacies. Lancaster University, 2009. p. 19

HAMILTON, Mary. Expanding the new literacy studies: using photographs to explore literacy as social practice. In: BARTON, David; HAMILTON, Mary; IVANIC, Roz (Org.) Situated literacies. London: Routledge, 2000a.

. Sustainable literacies and the ecology of lifelong learning, London, 2000b.

HEATH, S. B. What no bedtime story means: narrative skills at home and school. Language in Society, 1982.

INSTITUTO HOUAISS. Dicionário de língua portuguesa. São Paulo: Objetiva, 2001.

KLEIMAN, Angela. (Org.) Os significados do letramento: uma nova perspectiva sobre a prática social da escrita. Campinas: Mercado de Letras, 1995

Ação e mudança na sala de aula: uma pesquisa sobre letramento e interação. In:

ROJO, Roxane. (Org.) Alfabetização e letramento: perspectivas lingüísticas. Campinas/SP: Mercado das Letras, 1998. p. 173-204.

MASON, Jennifer. Qualitative researching. London: SAGE Publications, 1996.

MOITA-LOPES, L. P.. (Org.) Por uma lingüística indisciplinar. São Paulo: Parábola Editorial, 2006. 
OLABUÉNAGA, José Ignácio Ruiz; ISPIZUA, Maria Antonia. La decodification de la vida cotidiana. Universidade de Deusto: Bilbao, 1989.

OLIVEIRA, Maria do Socorro; KLEIMAN, Angela. (Org.) Letramentos múltiplos: agentes, práticas, representações. Natal/RN: Editora da UFRN, 2008.

RAJAGOPALAN, K. Repensar o papel da Lingüística Aplicada. In: MOITA-LOPES, Luiz Paulo da. (Org.) Por uma lingüística indisciplinar. São Paulo: Parábola Editorial, 2006. p. 149-166.

ROJO, Roxane. Letramentos múltiplos: escola e inclusão social. São Paulo: Parábola, 2009.

(Org.) Alfabetização e letramento: perspectivas lingüísticas. Campinas/SP: Mercado das Letras, 1998. P. 173-204.

SIGNORINI, I. A questão da língua legítima na sociedade democrática: um desafio para a Lingüística Aplicada contemporânea. In: MOITA-LOPES, Luiz Paulo da. (Org.) Por uma lingüística indisciplinar. São Paulo: Parábola Editorial, 2006. p. 169-189

SOARES, Magda. Letramento: um tema em três gêneros. Minas Gerais: Lê, 1998.

Alfabetização e letramento. São Paulo: Contexto, 2004a

Letramento e escolarização. In: RIBEIRO, Vera Masagão. Letramento no Brasil. São Paulo: Global, 2004b. p. 89-114.

STREET, Brian. Literacy in theory and practice. Cambridge: CUP, 1984.

Literacy practices and literacy myths. In: SALJO, R (Ed.) The written world: studies in literate thought and action Springer-Verlag: Berlim/Nova Iorque, 1988.

Abordagens alternativas ao letramento e desenvolvimento. Teleconferência Brasil sobre o letramento, outubro de 2003.

TFOUNI, Leda Verdiani. Letramento e alfabetização. São Paulo: Cortez, 1995.

TINOCO, Glicia Azevedo. Mundos de letramento de professores em formação no agreste norte-riograndense. In: OLIVEIRA, Maria do Socorro; KLEIMAN, Angela. Letramentos múltiplos. Natal/RN: UDUFRN, 2008. p.63-92. 